\title{
Programmed Catalytic Therapy-Mediated ROS Generation and T-Cell Infiltration in Lung Metastasis by a Dual Metal-Organic Framework (MOF) Nanoagent
}

\author{
Bhanu Nirosha Yalamandala ${ }^{1}$, Pin-Hua Chen ${ }^{1}$, Thrinayan Moorthy ${ }^{1}$, Thi My Hue Huynh ${ }^{1}$, \\ Wen-Hsuan Chiang ${ }^{2}$ (D) and Shang-Hsiu $\mathrm{Hu}^{1, *}$ \\ 1 Department of Biomedical Engineering and Environmental Sciences, National Tsing Hua University, \\ Hsinchu 30013, Taiwan; bhanunirosha@gmail.com (B.N.Y.); chen0922102113@gmail.com (P.-H.C.); \\ m.3nayan@gmail.com (T.M.); myhue100294@gmail.com (T.M.H.H.) \\ 2 Department of Chemical Engineering, National Chung Hsing University, Taichung 402, Taiwan; \\ whchiang@dragon.nchu.edu.tw \\ * Correspondence: shhu@mx.nthu.edu.tw
}

Citation: Nirosha Yalamandala, B.; Chen, P.-H.; Moorthy, T.; Huynh,

T.M.H.; Chiang, W.-H.; Hu, S.-H.

Programmed Catalytic

Therapy-Mediated ROS Generation and T-Cell Infiltration in Lung

Metastasis by a Dual Metal-Organic

Framework (MOF) Nanoagent.

Pharmaceutics 2022, 14, 527.

https://doi.org/10.3390/

pharmaceutics 14030527

Academic Editor: Sudip K. Das

Received: 20 January 2022

Accepted: 25 February 2022

Published: 27 February 2022

Publisher's Note: MDPI stays neutral with regard to jurisdictional claims in published maps and institutional affiliations.

Copyright: (C) 2022 by the authors. Licensee MDPI, Basel, Switzerland. This article is an open access article distributed under the terms and conditions of the Creative Commons Attribution (CC BY) license (https:// creativecommons.org/licenses/by/ $4.0 /)$.

\begin{abstract}
Nano-catalytic agents actuating Fenton-like reaction in cancer cells cause intratumoral generation of reactive oxygen species (ROS), allowing the potential for immune therapy of tumor metastasis via the recognition of tumor-associated antigens. However, the self-defense mechanism of cancer cells, known as autophagy, and unsustained ROS generation often restricts efficiency, lowering the immune attack, especially in invading metastatic clusters. Here, a functional core-shell metal-organic framework nanocube (dual MOF) doubling as a catalytic agent and $\mathrm{T}$ cell infiltration inducer that programs ROS and inhibits autophagy is reported. The dual MOF integrated a Prussian blue (PB)-coated iron $\left(\mathrm{Fe}^{2+}\right)$-containing metal-organic framework (MOF, MIL88) as a programmed peroxide mimic in the cancer cells, facilitating the sustained ROS generation. With the assistance of Chloroquine (CQ), the inhibition of autophagy through lysosomal deacidification breaks off the self-defense mechanism and further improves the cytotoxicity. The purpose of this material design was to inhibit autophagy and ROS efficacy of the tumor, and eventually improve T cell recruitment for immune therapy of lung metastasis. The margination and internalization-mediated cancer cell uptake improve the accumulation of dual MOF of metastatic tumors in vivo. The effective catalytic dual MOF integrated dysfunctional autophagy at the metastasis elicits the $\sim 3$-fold recruitment of $\mathrm{T}$ lymphocytes. Such synergy of T cell recruitment and ROS generation transported by dual MOF during the metastases successfully suppresses more than $90 \%$ of tumor foci in the lung.
\end{abstract}

Keywords: drug delivery; nano-catalytic medicine; MOF; autophagy; immune response; lung metastasis

\section{Introduction}

Metastasis is responsible for over $90 \%$ of cancer-related deaths [1,2]. It is developed in the primary tumor in which the cancer cell escapes from the immune system and forms the secondary tumor at distant organs [3-5]. Recently, immune therapy held promise to suppress the metastatic cells via the cytotoxic T lymphocytes [6-8]. Despite the recent advance in immunotherapy, the invading clusters of metastases usually smaller than $100 \mathrm{~mm}^{3}$ poorly performed vascularization and restricted physical contact of T lymphocytes, lowering immune responses [9-12]. Furthermore, the invasion of secondary tumors fills up the lymphatic vessels and reduces the space to recruit immune cells $[13,14]$. Thus, the recruitment of cancer-specific $\mathrm{T}$ lymphocytes during metastasis is critical.

To elicit T cells, a potential solution is to eliminate the cancer cells to generate a high number of cancer-associated antigens. In this regard, the reactive oxygen species (ROS), which plays a typical role in the cellular signaling-derivatized oxygen molecules, served as an oxidative damager in excessive expression (specifically $\mathrm{H}_{2} \mathrm{O}_{2}$ ), and could lead to 
potent oxidative harm within cancer cells $[15,16]$. Such ROS-responsive biological targets have attracted great attention in the redox chemistry of cancer therapeutics via promoting the intracellular $\mathrm{H}_{2} \mathrm{O}_{2}$ conversion to $\bullet \mathrm{OH}$ [17-19]. It can induce a Fenton-like reaction in the tumor in which $\mathrm{H}_{2} \mathrm{O}_{2}$ is disproportionated to toxic $\bullet \mathrm{OH}$, facilitating oxidization and damaging intracellular proteins and organelles [20]. However, the failure of proteins and organelles could simulate the genotoxic reaction and metabolic insufficiency [21], leading to the activation of autophagy (also known as the self-defense mechanism) [22,23]. In this mechanism, the cells engulf cytoplasmic organelles in autophagosomes and transport them to lysosomes for degradation. This helps the clearance of $\bullet \mathrm{OH}$-damaged proteins and organelles for detoxification [24,25].

To mitigate the activation of autophagy at tumors, different modified-MOFs have been developed as light- or sono-enhanced Fenton reactions [26,27]. The light-responsive materials possessing iron $\left(\mathrm{Fe}^{2+}\right.$ and $\left.\mathrm{Fe}^{3+}\right)$ under a NIR light or radiation were able to trigger the hydrogen peroxide to effectively produce hydroxyl radicals when compared to the traditional Fenton methods $[28,29]$. Such ROS generation by photo-reduction of $\mathrm{Fe}^{3+}$ ensures the proceeding of the reaction. For example, $\mathrm{Hu}$ et al. reported that the $\mathrm{Fe}^{2+}$-loaded lanthanide-doped porous particles under NIR irradiation to cause $\mathrm{Fe}^{2+}$ to produce localized $\bullet \mathrm{OH}$ radicals in cancer mitochondrion, showing the strong mtDNA damage [27]. In blocking the autophagic flux, chloroquine (CQ) has been developed as a classical inhibitor of autophagy [30]. The innate immunity provides downstream regulation of autophagy by activating the receptor that further enhances the production of cytokines and phagocytosis [31-33]. Conversely, in adaptive immunity, an increased source of antigens through autophagic activation promotes the $\mathrm{CD} 8^{+} \mathrm{T}$ cells for direct cytotoxicity in cancer metastasis [33]. The autophagy activation enhances the recruitment of LC3B protein (microtubule-associated protein 1 light chain 3B), the fusion between phagosomes and lysosomes leading to the increased antigen presentation for adaptive immunity [34]. Thus, the autophagic inhibition is required for preventing cargo degradation, which may help to promote the $\mathrm{T}$ cell infiltration in metastatic tumor suppression.

Here, a core-shell metal-organic framework nanocube (dual MOF) that integrated the features of programmed ROS and autophagy inhibition was developed for eliciting $\mathrm{T}$ cells towards tumor metastasis (Scheme 1). The dual MOF is able to program peroxide mimic in the cancer cells and can be sustained to generate ROS via the core-shell characteristics (step 1). With a high cellular uptake, the chloroquine (CQ) serves as an inhibitor of autophagy, and regulates the autophagy flux by de-acidifying the lysosomes, lowering the self-defense mechanism of cancer cells (known as autophagy) and boosting the intracellular oxidative damage (step 2). To trigger the therapeutic processes, $\mathrm{NH}_{2}-\mathrm{MIL}-88 \mathrm{~B}(\mathrm{Fe})$ as shell has been chosen as a highly efficient catalysis to guarantee the upstream generation of the amount of $\bullet \mathrm{OH}$ radicals, whereas Prussian blue (PB) as a core shows catalytic activity for the reduction of $\mathrm{H}_{2} \mathrm{O}_{2}$. The effective catalytic and dysfunctional autophagy at the metastasis could elicit the infiltration of T lymphocytes. The versatile dual MOF is an excellent ROS generator to actuate cancer cell death and enhance $\mathrm{T}$ cell recruitments for immune therapy. 


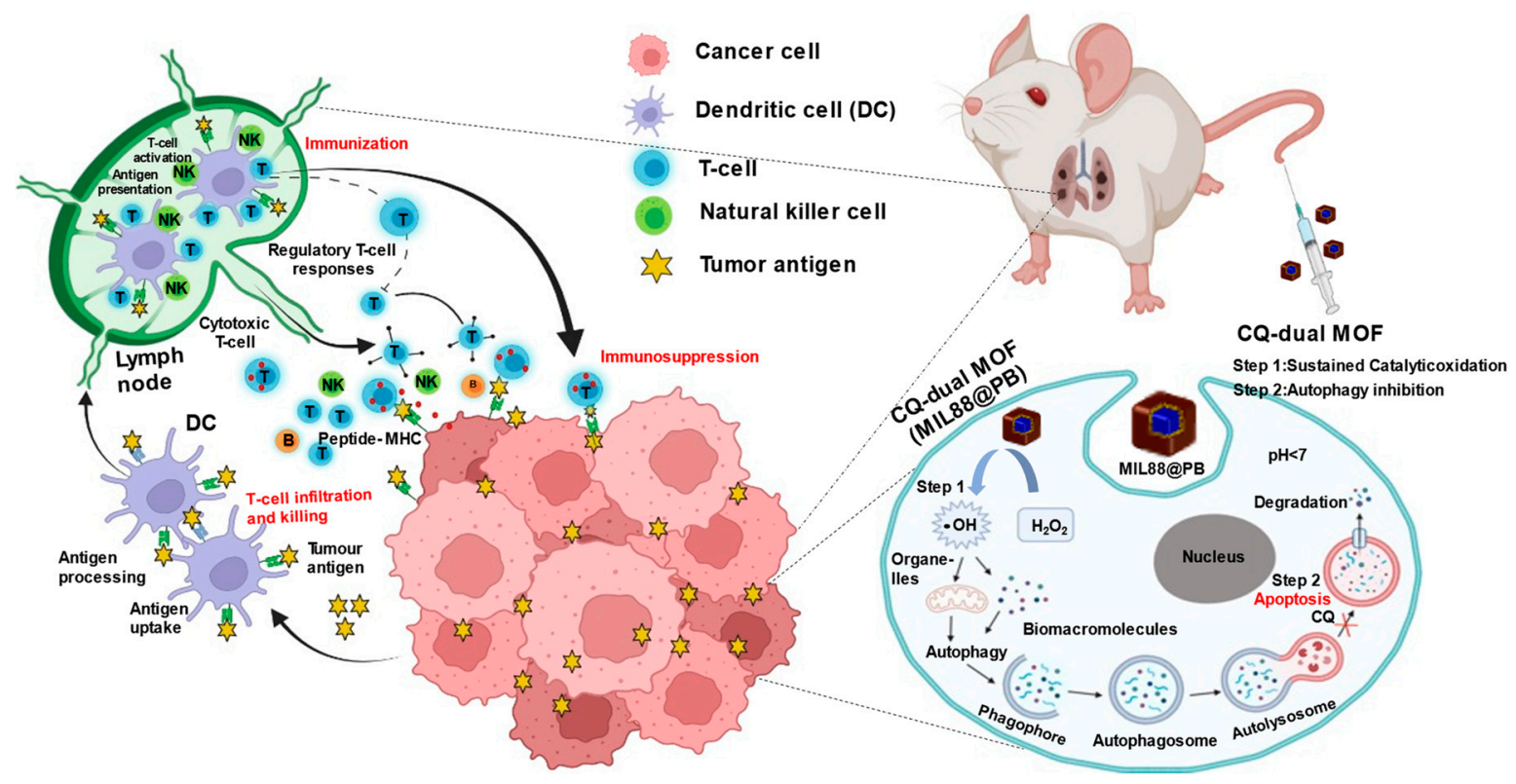

Scheme 1. Schematic illustration of dual MOF catalytic activity and immune response. The dual MOF programs peroxide mimic in the cancer cells and sustain to generate ROS via the core-shell characteristics (step 1). With a high cellular uptake, chloroquine (CQ) served as an inhibitor of autophagy, and regulates the autophagy flux by de-acidifying the lysosomes, lowering the selfdefense mechanism of cancer cells (step 2). The accumulation of dual MOF in lung metastasis promotes the accumulation of specific T-cell responses $\left(\mathrm{CD} 4^{+}\right.$and $\left.\mathrm{CD} 8^{+}\right)$.

\section{Method}

\subsection{Materials}

Polyvinylpyrrolidone (PVP, average molecular weight $(\mathrm{MW})=50,000 \mathrm{~g} / \mathrm{mol}$, SigmaAldrich, St. Louis, MO, USA), hydrochloric acid ( $\mathrm{HCl}, 36.0 \%$, Sigma-Aldrich), potassium ferricyanide $\left(\mathrm{K}_{3}\left[\mathrm{Fe}(\mathrm{CN})_{6}\right]\right.$, Sigma-Aldrich), pluronic (F127, Sigma-Aldrich), iron (III) chloride hexahydrate $\left(\mathrm{FeCl}_{3} \cdot 6 \mathrm{H}_{2} \mathrm{O}\right.$, Sigma-Aldrich), acetic acid $\left(\mathrm{CH}_{3} \mathrm{COOH}\right)$, and aminoterephthalic acid ( $\mathrm{NH}_{2}-\mathrm{BDC}$, Thermo Fisher Scientific, Lancashire, UK). Chloroquine (CQ) was obtained from Sigma-Aldrich. Aqueous solutions were prepared with deionized (D.I.) water $(17.7 \mathrm{MU} \mathrm{cm})$ produced from Milli-Q water purification. All other chemicals used in this work were obtained from commercial suppliers which were of analytical grade and used without any further purification.

\subsection{Synthesis of $P B M O F$}

The synthesis procedure of Prussian blue (PB) was carried out via a modified approach developed by Yamauchi group [35]. In a typical process, $3 \mathrm{~g}$ of PVP and $0.2267 \mathrm{~g}$ of $\mathrm{K}\left[\mathrm{Fe}(\mathrm{CN})_{6}\right]$ were dissolved into $40 \mathrm{~mL}$ D.I. water under vigorous stirring and then $35.0 \mu \mathrm{L}$ of $\mathrm{HCl}$ was added to form a clear solution. The resulting solution was continuously stirred for $30 \mathrm{~min}$ and placed into an autoclave at $80^{\circ} \mathrm{C}$ for $20 \mathrm{~h}$. The mixture was washed many times with ethanol and the resultant product was dried by particle lyophilization.

\subsection{Synthesis of $\mathrm{NH}_{2}-\mathrm{MIL} 88$}

The synthesis procedure of $\mathrm{NH}_{2}-\mathrm{MIL} 88 \mathrm{~B}(\mathrm{Fe})$ was carried out via a hydrothermal route by dissolving $0.1783 \mathrm{~g}$ of $\mathrm{FeCl}_{3}$ and $0.16 \mathrm{~g}$ of F127 in $15 \mathrm{~mL}$ of D.I. water. After $45 \mathrm{~min}$ of stirring, $150 \mu \mathrm{L}$ of acetic acid was added to regulate the size of nanoparticles followed by another $45 \mathrm{~min}$ of stirring. Then, $60 \mathrm{mg}$ of $\mathrm{NH}_{2}-\mathrm{BDC}$ was added to the mixture for the further stirring of $2 \mathrm{~h}$, and the resulting mixture was transferred to an autoclave at $110{ }^{\circ} \mathrm{C}$ for $16 \mathrm{~h}$. After aging, the mixture was washed several times with D.I. water and the resultant was obtained by particle lyophilization. 


\subsection{Synthesis of MIL88@PB (Dual MOFs)}

The dual MOFs were synthesized via the hydrothermal route by coating the PB with $\mathrm{NH}_{2}$-MIL88B (Fe) MOF as an outer shell through a layer-growth method. Briefly, $17.83 \mathrm{mg}$ of $\mathrm{FeCl}_{3} \cdot 6 \mathrm{H}_{2} \mathrm{O}$ and $3.75 \mathrm{mg}$ of $\mathrm{F} 127$ were added to $4 \mathrm{~mL}$ of D.I. water, and this mixture was further added to $28 \mathrm{~mL}$ of PB solution $(0.00813 \mathrm{~g} / \mathrm{mL})$. After $1 \mathrm{~h}$ of stirring, $37.5 \mu \mathrm{L}$ of acetic acid was added, followed by another $1 \mathrm{~h}$ of stirring. Then, $6 \mathrm{mg}$ of $\mathrm{NH}_{2}-\mathrm{BDC}$ was added. After continuous stirring of $2 \mathrm{~h}$, the resulting mixture was autoclaved at $110^{\circ} \mathrm{C}$ for $16 \mathrm{~h}$. After aging, the mixture was washed by ethanol and D.I. water for three times, and the precipitates were collected. The final product was obtained by particle lyophilization.

\subsection{Characterizations}

The morphologies of PB, MIL88 and MIL88@PB nanoparticles were analyzed by field emission scanning electron microscopy (FE-SEM) and cryo-high-resolution transmission electron microscope (Cryo-HRTEM, JEM-2010, JEOL, Tokyo, Japan). Nanoparticle's diameter and surface charge were analyzed by dynamic light scattering (DLS, Nano-ZS, Malnern, Malvern, UK). Powder X-ray diffraction (XRD) patterns were tested on a Rigaku Japan TTRAX III equipped with $\mathrm{Cu}$ Ka radiation of 2 theta range. Fourier-Transform infrared (FTIR) spectrum was analyzed in the range of $500-4000 \mathrm{~cm}^{-1}$ with a resolution of $4 \mathrm{~cm}^{-1}$.

\subsection{In Vitro Drug Release}

To load CQ into the dual MOF nanoparticles, the nanoprecipitation method with $2 \mathrm{mg}$ of PB, MIL88, and dual MOFs dissolved into $15 \mathrm{~mL}$ of PBS solution by adding $1.8 \mathrm{mg}$ of CQ. The drug release test was carried out by collecting $2 \mathrm{~mL}$ of supernatant by washing the mixture for UV-vis absorption (The Evolution 350 UV-Vis Spectrophotometer, Therma Fisher Scientific). The mixture was replaced with fresh $2 \mathrm{~mL}$ of PBS solution. The experiment was carried out for $50 \mathrm{~h}$ to measure the drug encapsulation efficiency.

\subsection{In Vitro Cellular Toxicity}

A total of $100 \mu \mathrm{L}$ of B16F10 (a murine tumor cell line; skin melanoma cells) cells at a density of $1 \times 10^{4}$ cells per well were seeded into 96-well plates using standard cell medium (DMEM) and incubated for $24 \mathrm{~h}$ in $5 \% \mathrm{CO}_{2}$ at $37^{\circ} \mathrm{C}$. Then, the cells were treated with $100 \mu \mathrm{L}$ of MOF nanoparticles at different concentrations $(12.5,25,50,75$ and $100 \mu \mathrm{g} / \mathrm{mL})$ for another $24 \mathrm{~h}$. Cells were washed carefully three times with PBS solution and cell cytotoxicity assay was carried out by adding $10 \mu \mathrm{L}$ of MTT Presto blue solution to each well incubated for 10-15 min before. Finally, a plate reader (Synergy HT Multidetection microplate reader, BioTek Instruments, Inc., Santa Clara, CA, USA at a wavelength of $570 \mathrm{~nm}$ ) was used to measure the absorbance of each well and expressed the percentage of cell viability.

\subsection{In Vitro Cellular Uptake}

For the cellular uptake experiment, $20 \mu \mathrm{L}$ of quantum dots (QDs) was loaded into PB, MIL88, and dual MOF with different concentrations (75, 100, 200 and $400 \mu \mathrm{g} / \mathrm{mL}$ ). The QD-labeled MOFs were added to $1 \times 10^{5}$ of B16F10 cells which were seeded on coverslip in 6-well plates for $24 \mathrm{~h}$. The medium was replaced with $1 \mathrm{~mL}$ of MOFs solution and further incubated for $24 \mathrm{~h}$ at $37^{\circ} \mathrm{C}$. Then, the staining method is carried out by replacing the $1 \mathrm{~mL}$ of medium with $3 \%$ formaldehyde solution to fix the cells for $30 \mathrm{~min}$ of incubation. Subsequently, the cell solution was removed, and $1 \mathrm{~mL}$ of Triton $(0.1 \%)$ was added for $30 \mathrm{~min}$ of incubation for permeabilization. Finally, the cell nuclei and cytoskeleton were stained by $1 \mathrm{~mL}$ of DAPI $(1 \mu \mathrm{g} / \mathrm{mL})$ for $20 \mathrm{~min}$ and F-actin $(300$ units $/ \mathrm{mL})$ overnight at $37^{\circ} \mathrm{C}$. Between each step, the cells were washed carefully with PBS three times. The cells were mounted on glass slides and observed by confocal laser scanning microscopy (CLSM Zeiss LSM 800, Oberkochen, Germany). 


\subsection{In Vitro LC3B Autophagy Protein Expression (Regulation of Autophagosomes)}

LC3B, an autophagy protein on autophagosome, expression was evaluated. CQloaded PB, MIL88, and dual MOFs at different concentrations were treated to B16 cells to investigate the activity of autophagosomes and fusion with lysosomes. The QD-labeled MOFs were added to $1 \times 10^{5}$ green fluorescence-expressed B16F10 (GFP-B16F10) cells, which were seeded on a coverslip in 6-well plates for $24 \mathrm{~h}$. The medium was replaced with $1 \mathrm{~mL}$ of MOF solution and further incubated for $24 \mathrm{~h}$ at $37^{\circ} \mathrm{C}$. Then, the staining method was carried out by removing the $1 \mathrm{~mL}$ of medium and adding $3 \%$ formaldehyde solution to fix the cells for $30 \mathrm{~min}$ incubation. After that, the cell solution was replaced with $1 \mathrm{~mL}$ of Triton $(0.1 \%)$ and $20-30 \mathrm{~min}$ incubation for permeabilization. The cell nuclei and cytoskeleton were stained with $500 \mu \mathrm{L}$ per well with DAPI $(1 \mu \mathrm{g} / \mathrm{mL})$ and F-actin (300 units $/ \mathrm{mL}$ ) for $2 \mathrm{~h}$, and then, $1 \mathrm{~mL}$ of LC3B primary antibody was added with $5 \%$ of blocking buffer bovine serum albumin (BSA) overnight at $4{ }^{\circ} \mathrm{C}$, respectively. Finally, secondary antibody (LC3B) was added with blocking buffer (BSA) for $1 \mathrm{~h}$ of incubation. The cells were mounted on glass slides and tested the MOF treated autophagosome activation by Confocal laser scanning microscopy (CLSM Zeiss LSM 800, Oberkochen, Germany).

\subsection{In Vitro Catalytic Performance of Dual MOFs}

The catalytic performance of MOFs by detection of $\bullet \mathrm{OH}$ radicals in vitro was evaluated by demising methylene blue (MB) method. It was tested at $\mathrm{pH} 6.4$ and 7.4 by adding $100 \mu \mathrm{g} / \mathrm{mL}$ of PB, MIL88, and dual MOFs into $250 \mu \mathrm{L}$ of glutathione (GSH, $40 \mu \mathrm{M})$ and $100 \mu \mathrm{L}$ of $\mathrm{H}_{2} \mathrm{O}_{2}$ solution. Methylene blue of $50 \mu \mathrm{L}(500 \mu \mathrm{M})$ was added to detect the ROS generation in addition to MOF. The MOF catalytic activation was measured by UV-Vis Absorption. The experiment was conducted for $4 \mathrm{~h}$ to detect the initiation of Fenton reaction and catalytic activation of MOFs.

\subsection{Tissue Section Immunostaining}

Animal study and surgical procedures were performed in accordance with the protocol approved by the Institutional Animal Care and Use Committee (IACUC), National Tsing Hua University, Hsinchu, Taiwan (IACUC protocol and approval number are 10704). Female C57BL/ 6 mice of 6 to 8 weeks old (purchased from National Laboratory Animal Center, NLAC, Taiwan) were adopted as the animal model of tumor growth inhibition experiment. For the development of mouse lung metastasis, $1 \times 10^{6} \mathrm{GFP}-\mathrm{B} 16 \mathrm{~F} 10$ cells were trypsinzed, washed, and suspended in DMEM in advance. Then, $100 \mu \mathrm{L}$ of $1 \times 10^{6} \mathrm{GFP}-$ B16F10 cells resuspended with PBS was injected to the mouse intravenously. After 13 days of cancer cell injection, the QD-labeled PB, MIL88, or dual MOF nanoparticles were injected into the mice. Then, $24 \mathrm{~h}$ post injection, the mouse was sacrificed, and lung tissue was surgically excised to make a frozen section. The organs were perfused in PBS and further transferred to $4 \%$ paraformaldehyde overnight at $4{ }^{\circ} \mathrm{C}$. Subsequently, they were fixed in OCT gel at $-80{ }^{\circ} \mathrm{C}$ for frozen section slicing. Dehydrated frozen tissue was carried by immersing it for $10 \mathrm{~min}$ with $100 \%$ methanol. The slices were washed with PBS (Gibco, 10010023) to remove the OCT residue. Before staining, $100 \mu \mathrm{L}$ of blocking buffer (BSA) was added and incubated for $1 \mathrm{~h}$ at room temperature. Then, $100 \mu \mathrm{L}$ of diluted primary antibody CD8 (Rabbit-anti CD8 $\alpha$, Abcam, ab217344, 1:1000 dilution) and CD4 (Rat-anti CD4, Abcam, ab25475, 1:1000 dilution) were added and incubated overnight at $4{ }^{\circ} \mathrm{C}$. After $24 \mathrm{~h}$, the secondary antibody CD8 (Donkey anti-rabbit 488, Jackson, 112545143) and CD4 (Donkey anti-rat 647, Jackson, 112605167) were added to samples for another $1 \mathrm{~h}$ of incubation. Between each step, the slices were washed for three times carefully with $1 \times$ PBS solution through an autoshaker. DAPI mounting medium (Abcam, ab104139) was used and the slide was sealed with nail polish. The tissue images were captured with Confocal laser scanning microscopy (CLSM Zeiss LSM 800, Oberkochen, Germany). 


\subsection{In Vivo Flow Cytometry Analysis}

The in vivo flow cytometry analysis was plied to examine $\mathrm{T}$ cells in lung metastasis. Briefly, $100 \mu \mathrm{L}$ of $1 \times 10^{6}$ GFP-B16F10 cells resuspended with PBS was injected to the mouse intravenously. For the treatment groups, the NPs were injected via a 27-gauge needle through a tail vein 13 days post implantation of a tumor. After $24 \mathrm{~h}$, the mice were sacrificed on the 14th day and the lungs were dissected for immune staining. The isolated tissues were mechanically disrupted and were added into the RBC lysis buffer for lyses red cells. Then, to attain tumor single-cell suspensions, enzymatic digestion in $0.1 \mathrm{mg} / \mathrm{mL}$ collagenase solution (Sigma, C0130), $0.1 \mathrm{mg} / \mathrm{mL}$ Liberase solution (TL Roche), $1 \mu \mathrm{g} / \mathrm{mL}$ DNase solution (Sigma, DN25), and $6.6 \mu \mathrm{g} / \mathrm{mL}$ dispase I solution (Sigma, D4818) in HBSS buffer (Sigma, H8264) for $30 \mathrm{~min}$. The suspension was filtered through a $70 \mu \mathrm{M}$ filter after digestion to remove the cellular debris. For B16F10 cells, the formed single-cell suspension was then stained with fluorochrome-labeled antibodies were analyzed by flow cytometry after the surface staining for $30 \mathrm{~min}$ at $4{ }^{\circ} \mathrm{C}$. The characterization of the T cell subsets was performed using fluorochrome conjugated anti-mouse Abs: anti-CD4 PE (BD, 553730), anti-CD3e FITC (BD, 553062), anti-CD8a APC (BD, 553035), and anti-CD45 PE-Cy7 (BD, 552848). The isolated spleen was mechanically disrupted and added into RBC lysis 40 buffer for lyses red cells. Then, to attain tumor single-cell suspensions and to remove debris, the suspension was filtered through a $70 \mu \mathrm{M}$ cell strainer. The characterization of the matured DC cell subsets was performed using antibody anti-mouse CD11c-FITC (BD, 553801), anti-Mouse CD80-APC (BD, 560016), and anti-MouseCD86-PE-Cy7(BD,560582). Data were acquired using a BD FACSAriaTM II flow cytometer (Invitrogen, Thermo Fisher Scientific, Oregon, USA) and analyzed with Flow Jo software (version 7.6.1).

\section{Results and Discussion}

\subsection{Characterization of $P B, M I L 88$, and Dual MOF Nanoparticles}

The dual MOFs mainly consisted of two elements, PB nanocubes and MIL88 shells, as shown in Figure 1a. To investigate the morphologies of resulting particles, scanning electron microscopy (SEM) and transmission electron microscopy (TEM) were applied. SEM and TEM images reveal the surface characteristics of PB, MIL88, and MIL88@PB with their morphologies of cubes and bipyramidal hexagons (Figure 1b-m). The sizes of PB nanocubes were ranged from 200 to $260 \mathrm{~nm}$, showing a smooth and sharp surface on its structure (Figure 1b-d). As revealed in Figure 1e-g, MIL88 exhibited monodisperse bipyramidal hexagons with an average length of $130 \mathrm{~nm}$. After MIL88 coating, dual MOFs could maintain the cubic structures as PB (Figure 1h,i), but a clear shell constructed by MIL88 was observed in TEM analysis (Figure 1m). The well-coating of MIL88 on PB was potentially attributed to the affinity of molecule absorption between PB and MIL88 precursors. The evidence from elemental mappings also indicated that the elements of $\mathrm{Fe}$, $\mathrm{N}$, and $\mathrm{C}$ were distributed on the dual MOFs (Figure $1 \mathrm{n}-\mathrm{p}$ ), implying the successful coating of two materials.

The growth of dual MOF also reflected the size distribution of PB, MIL88, and dual MOFs, where the hydrodynamic diameter of PB, MIL88, and dual MOFs displayed 144, 185, and $296 \mathrm{~nm}$ in agreement with the DLS technique, respectively (Figure 2a). The zeta potential results of PB, MIL88, and dual MOFs showed the surface charge of -1.07 , -1.59 , and -6.53 (Figure $2 b$ ). The lower surface charge of dual MOF was probably partly caused by the defects of MIL88, since the crystallinity of MIL88 on PB was decreased (as demonstrated on TEM, Figure $1 \mathrm{~m}$ ). Furthermore, the chemical bonds of dual MOFs, representing the binding energy at 711 and $721 \mathrm{eV}$ corresponding to the Fe2 $\mathrm{p}_{1 / 2}$ and $\mathrm{Fe} 2 \mathrm{p}_{3 / 2}$, suggested that all $\mathrm{Fe}$ atoms in dual MOFs were in the trivalent state specifying their interactions with the organic ligand, 2-Aminoterephtalic acid (Figure 2c,d). Furthermore, Fourier-transform infrared (FTIR) spectrum results revealed that a strong peak at $2090 \mathrm{~cm}^{-1}$ (Figure 2e) in $\mathrm{PB}$ and dual MOF, indicating the stretching absorption of $\mathrm{CN}$ bands from the PB. The absorption bands at $1156-1096 \mathrm{~cm}^{-1}$, which is attributed to the stretching vibration of C-O in the backbone of Pluronic F127 (Figure 2e, MIL88). Four absorption 
bands at $1585,1495,1436$, and $1381 \mathrm{~cm}^{-1}$ are attributed to the symmetric and asymmetric vibrations of carboxyl groups. In addition, two bands at 3466 and $3363 \mathrm{~cm}^{-1}$ could be observed as the characteristics of symmetric and asymmetric stretching absorptions of primary amine groups of $\mathrm{NH}_{2}$-BDC linkers. Meanwhile, dual MOF displayed the functional groups of inner PB layer and outer MIL88, respectively. Next, the crystal structures of three particles were evaluated by X-ray diffraction (XRD, Figure 2f). XRD analysis of PB exhibited the major diffraction planes at (200), (220), and (400), which are the characteristic of the PB crystal planes indexed face-centered cubic lattice (Figure $2 \mathrm{f}$ in symbol diamond). After coating with MIL88, dual MOF revealed both the diffraction pattern of PB and MIL88 without any changes, indicating the slight effects of coating process in crystallinity. The lower XRD intensity of PB in dual MOF was caused by the shield effects of MIL88 on PB. The MOF is an instable material in the presence of water. In our study, the preservation of materials was carried out by the drying process under a vacuum to avoid the hydrolysis. The hydrolysis could lead the breaking of $\mathrm{Fe}-\mathrm{O}$ bonds and exposing more $=\mathrm{C}-\mathrm{H}$ groups [36]. The colloidal stability of PB, MIL88, and dual MOF in cell culture medium (DMEM supplemented with $10 \%$ FBS serum) for $24 \mathrm{~h}$ were also estimated to understand the process (Figure S1). The variation of size and surface charge could be observed in both MIL88 and dual MOF, indicating the hydrolysis effect.

(a) I. PB
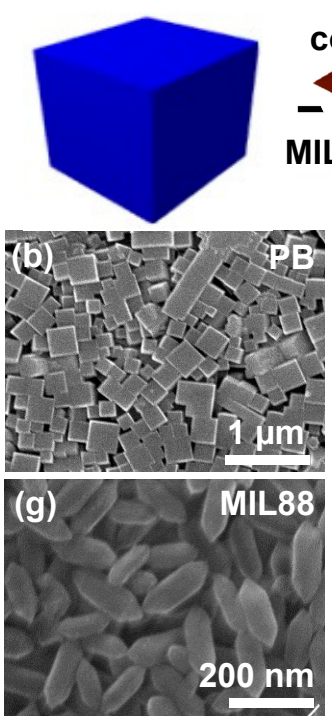

(1)

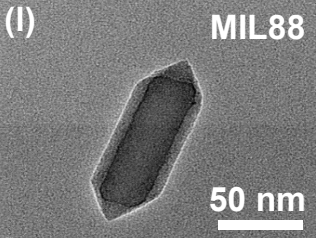

II. MIL88@PB (dual MOF)
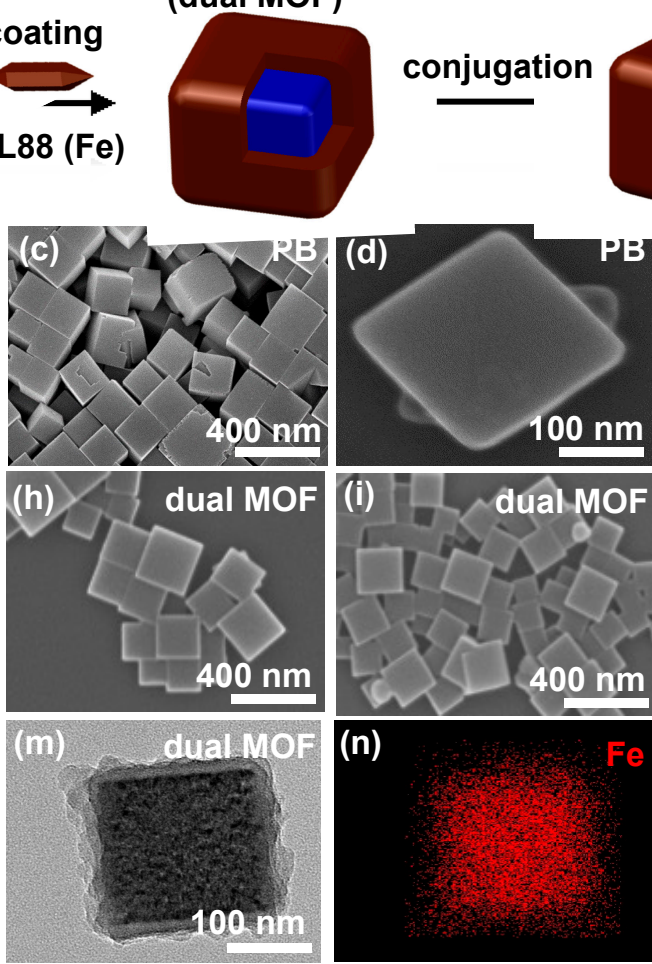

III. CQ-dual MOF
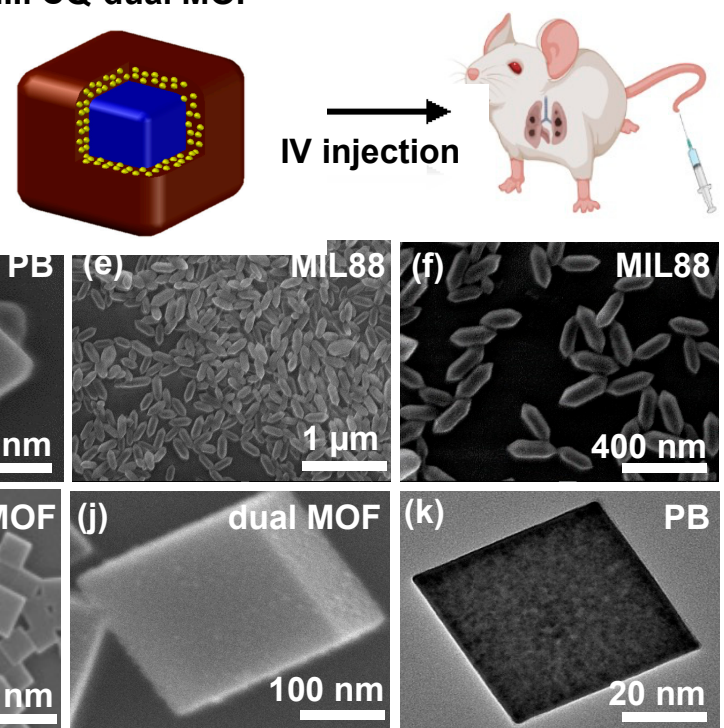

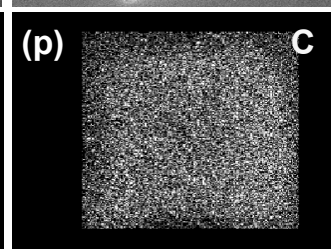

Figure 1. Synthesis and characterizations of dual MOFs. (a) The schematic illustration of the synthesis process of CQ-loaded dual MOF (CQ-dual MOF). The dual MOF system was reached by coating the inner Prussian blue (PB) with an outer MIL88 as a metal source and $\mathrm{NH}_{2} \mathrm{BDC}$ as an organic linker while. F127 pluronics and acetic acid were used for stability and tailoring the size of the MOF. (b-i) SEM and (j-m) TEM images of PB, MIL88, and dual MOFs. (n-p) Element mapping analysis of dual MOFs. 
(a)

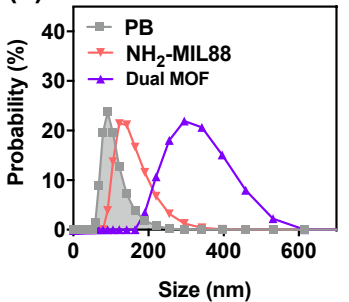

(e)

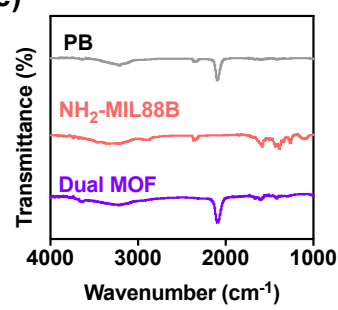

(b)

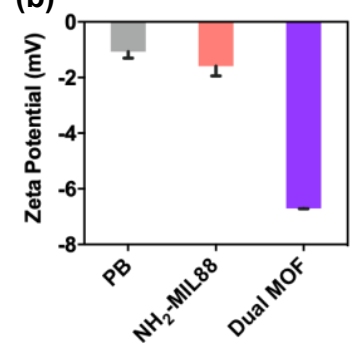

(f)

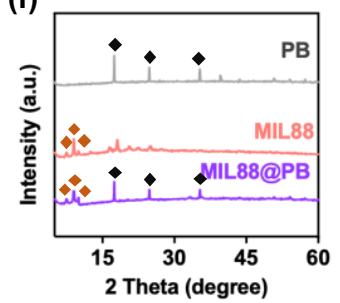

(c)

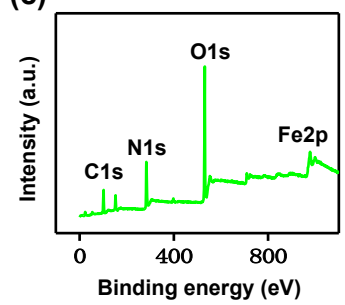

(g)

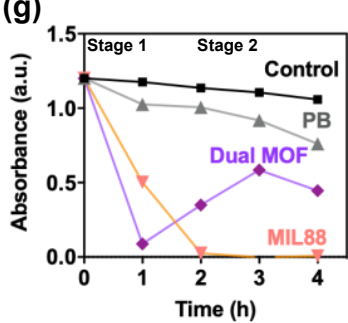

(d)

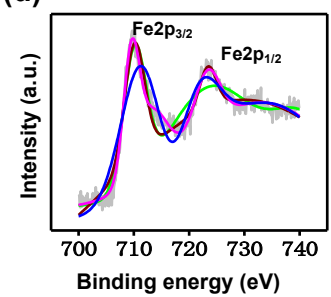

(h)

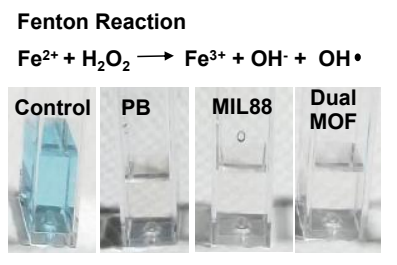

Figure 2. Characterizations of single and dual MOFs. (a) Size distribution and (b) zeta potential ofPB, MIL88, and dual MOFs. (c) XPS spectrum of all the elements and (d) Fe2p spectrum of dual MOFs, demonstrating all the iron components in the trivalent state. (e) FTIR and (f) X-ray diffraction spectrum of $\mathrm{PB}(\bullet), \operatorname{MIL} 88(\diamond)$, and dual MOF. Slight disappearances reflections of 2-Theta and intensities in the dual MOF were due to the shielding effect of MIL88 on PB. (g,h) Catalytic performance of control, PB, MIL88, and dual MOF.

The catalytic performance of PB, MIL88, and dual MOFs were investigated by the detection of $\bullet \mathrm{OH}$ radicals. The experiments via adding MOFs into $\mathrm{H}_{2} \mathrm{O}_{2}$ solution were performed for $4 \mathrm{~h}$ at $\mathrm{pH} 6.4$ and 7.4, respectively. Methylene blue (MB), a detecting dye, is added to evaluate ROS generation in the reaction mixture to understand Fenton reaction. Generally, the iron-based MOF reacted with $\mathrm{H}_{2} \mathrm{O}_{2}$ turn to ferric ions and release - $\mathrm{OH}$ radicals, facilitating the $\mathrm{MB}$ reaction and turning it into reaction color. This also confirms that MOFs can catalytically activate $\mathrm{H}_{2} \mathrm{O}_{2}$ to produce $\bullet \mathrm{OH}$ radicals. At $\mathrm{pH}$ 6.4, MIL88 initiated the Fenton reaction immediately and consumed all ferric ions within 1 $\mathrm{h}$, exhibiting no higher reaction ability over time (Figure 2g,h). Compared to MIL88, PB exhibited the slower Fenton reaction rate and sustained generation of ROS for four hours. Dual MOF performed the programmed ROS generation to manipulate the Fenton reaction, which demonstrated the strong Fenton reaction in the first hour and sustained reaction for another $3 \mathrm{~h}$. The dual MOF catalytic activation happened through the various dynamics of electron transfer initiated by Fenton reaction in MIL88 and PB. We further tested the MOF catalytic activity at $\mathrm{pH}$ 7.4, which showed no significant reaction; only a weak Fenton reaction occurred.

\subsection{In Vitro Drug Release}

To measure the encapsulation efficiency, the supernatant of loading drug was collected by centrifugation of the mixture. The CQ loading efficiency was calculated by measuring the initial drug and released drug in supernatant with time different points. Due to the MOF having the porous structures with the affinity to CQ via the $p-p$ interactions and van der Waal forces, the resulting loading efficiency reached about $\sim 70 \%$. The loading content was kept in a similar concentration at $1 \mathrm{mg} / \mathrm{g}$ particles for three types of particles for the comparison of treatment effects. The release profiles were shown in Figure S2, which displayed the sustained release patterns for each group.

\subsection{In Vitro Cellular Uptake and Cytotoxicity of PB, MIL88, and Dual MOF}

$\mathrm{PB}, \mathrm{MIL} 88$, and dual MOF were incubated with B16F10 (a murine tumor cell line; skin melanoma cells) for $24 \mathrm{~h}$ to verify the cell uptake. CdSe quantum dots (QDs) was loaded into the particles by the hydrophobic interaction for tracking their intracellular behaviors. 
After $24 \mathrm{~h}$ of incubation, CLSM was applied to evaluate the cellular uptake, in which the nucleus and cytoskeleton were stained by DAPI and F-actin, respectively. CLSM images of B16F10 cells in Figure 3a displayed that only few PBs were observed in the cytoplasm. For MIL88 and dual MOF groups, the amounts of particles in the cells were higher than PB group. As documented in literature, the rod-like nanoparticles (such as MIL88) with the anisotropic properties could enhance the internalization efficiency in a lying-down or standing-up manner [37]. On the other hand, dual MOF possessed the negative charges which improved the nonspecific interactions with the plasma membrane [38,39]. Therefore, the two types of particles improved the cell uptake efficiency. The results of flow cytometry were also used to quantify the cell uptake in Figure 3b, indicating the stronger accumulation of MIL88 and dual MOF in B16F10.

(a)

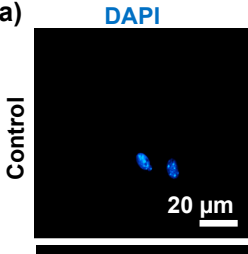

$\stackrel{m}{a}$
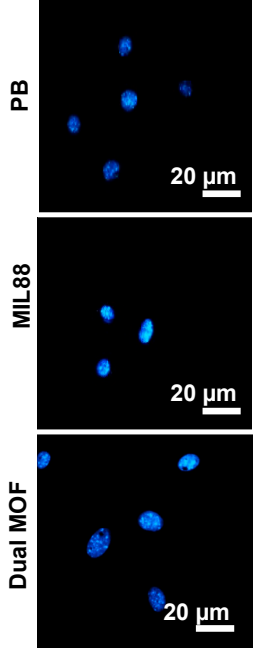

F-actin
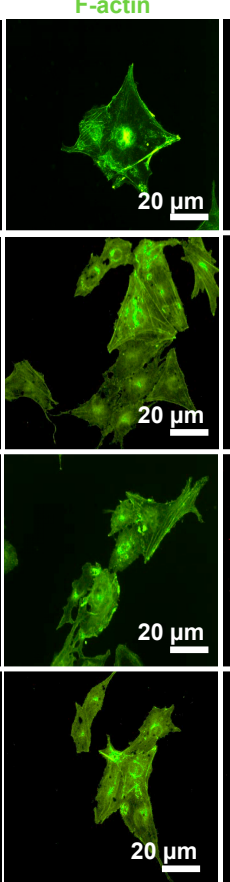
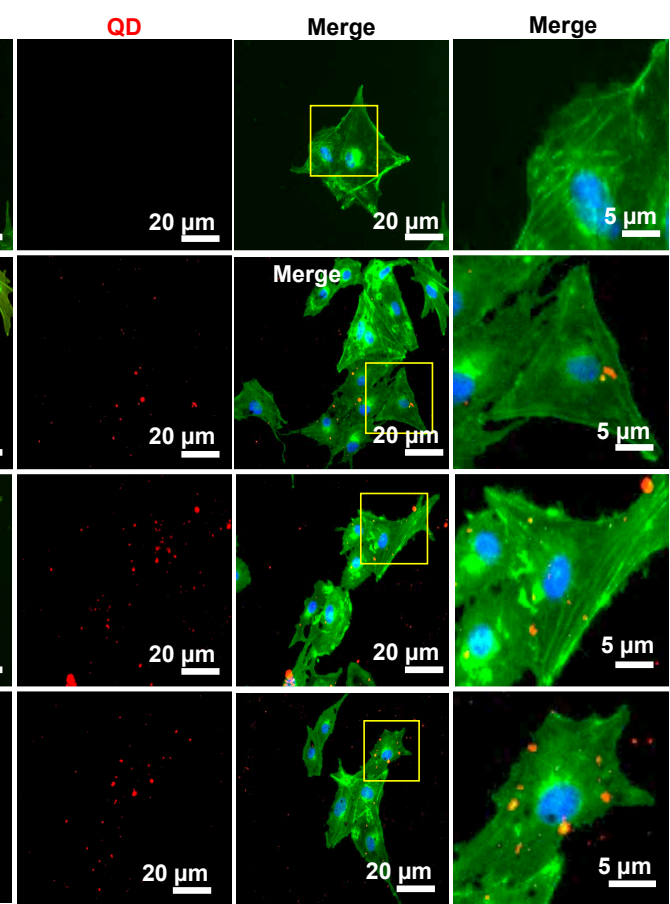

(b)

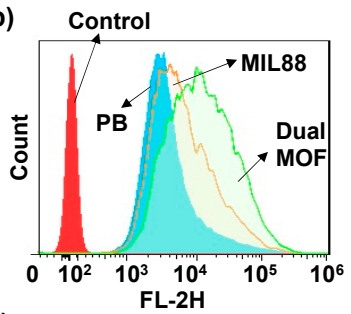

(c)
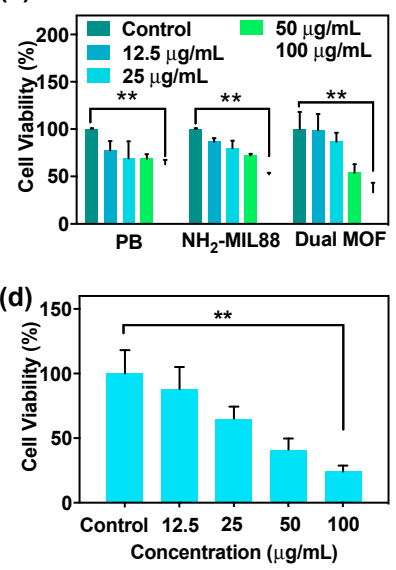

Figure 3. (a) CLSM images of cellular uptake of B16F10 incubated with PB, MIL88, and dual MOF labeled by QDs. Blue, red, and green fluorescence represent nucleus staining with DAPI, particle staining with QDs, and cytoskeleton staining with F-actin, respectively. (b) Flow cytometry analysis of PB, MIL88, and dual MOF after $24 \mathrm{~h}$ of incubation in B16F10 cells. (c) Cell viability of B16F10 cells in the presence of PB, MIL88, and dual MOF solution at various concentrations. (d) Cytotoxicity of B16F10 cells incubated with CQ-loaded dual MOF at various concentrations. Quantitative significant statistical data were calculated via Student's $t$-test, ${ }^{* *} p<0.01$.

The cytotoxicity of PB, MIL88, and dual MOF was examined by incubating particles with B16F10 (a murine tumor cell line; skin melanoma cells) at various concentrations for $24 \mathrm{~h}$. The in vitro cell cytotoxicity studies of three groups were tested by using MTT assay. The results demonstrate that the dual MOFs showed higher cytotoxicity compared to the remaining groups. Compared to the control group, all the three groups increase the cytotoxicity when increasing MOFs concentration (Figure 3c). Conversely, the dual MOF group at $100 \mu \mathrm{g} / \mathrm{mL}$ showed significant cytotoxicity compared to the PB and MIL88 groups, which might be caused by programmed ROS generation effects of dual MOF. The outer coating shell, i.e., MIL88, not only had the ability of loading CQ but also increased the cell cytotoxicity (Figure 3d). 


\subsection{In Vitro Cellular Uptake and LC3B Protein Expression (Regulation of Autophagosomes)}

LC3B, an autophagic marker, also known as Atg8 protein, is associated with complete autophagosome formation. Therefore, increased LC3B is a good indication for autophagososme formation [30], and LC3B protein expression reflects the regulation of autophagosomes. While MOFs entered the tumor region, the cancer cells interacted with the ferric ions of MOFs could trigger the initiation of Fenton reaction, converting excessive intrinsic non-toxic $\mathrm{H}_{2} \mathrm{O}_{2}$ into highly oxidative $\bullet \mathrm{OH}$ radicals. The release of $\bullet \mathrm{OH}$ radical attacks and inactivates organelles and proteins. On this basis, autophagic responses are activated through the recruitment of LC3B proteins to degrade the proteins and organelles. To confirm the recruitment, LC3B protein expression of B16F10 treated by PB, MIL88, and dual MOFs were evaluated by CLSM. As shown in Figure 4a, CLSM images demonstrated that three groups (PB, MIL88, and dual MOFs) can actuated the LC3B expression when compared to control group, whereas dual MOFs showed slightly higher expression of LC3B compared to other groups, indicating the activation of autophagososmes. Furthermore, the expression of LC3B quantified by Image J software also reflected the results (Figure $4 \mathrm{~b}$ ). As documented in the literature, pre LC3B cleaved to form LC3-I by Atg 4 and activated by Atg7 protein to form LC3-II. An increased expression of LC3-II demonstrates increased autophagy [40]. Autophagy-regulated proteins (LC3B/Atg8, Beclin-1/Atg6, Atg7, Lamp-2, p62, and aggregates of polyubiquitin) in autophagosome formation and lysosomal fusion (Figure 4c).

(a)

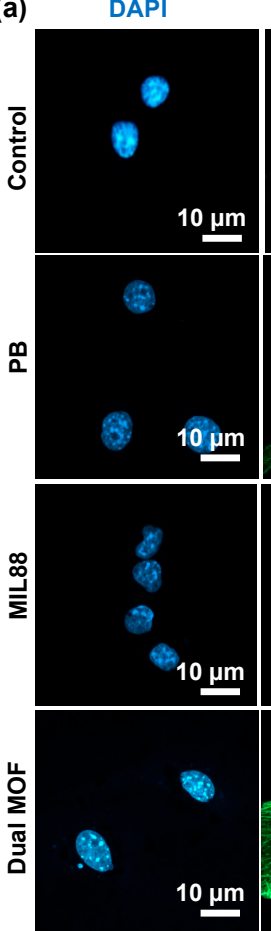

F-actin

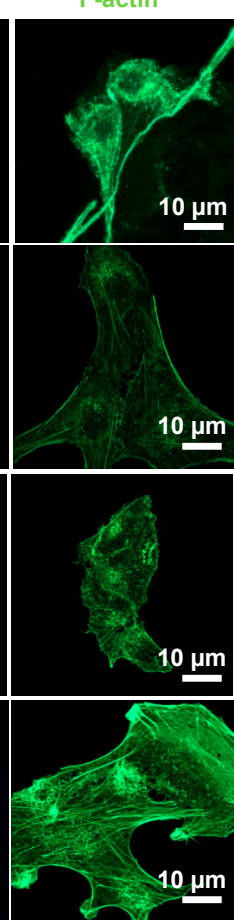

QD

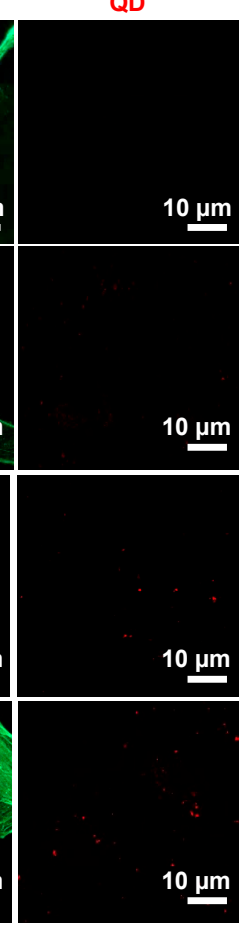

LC3B

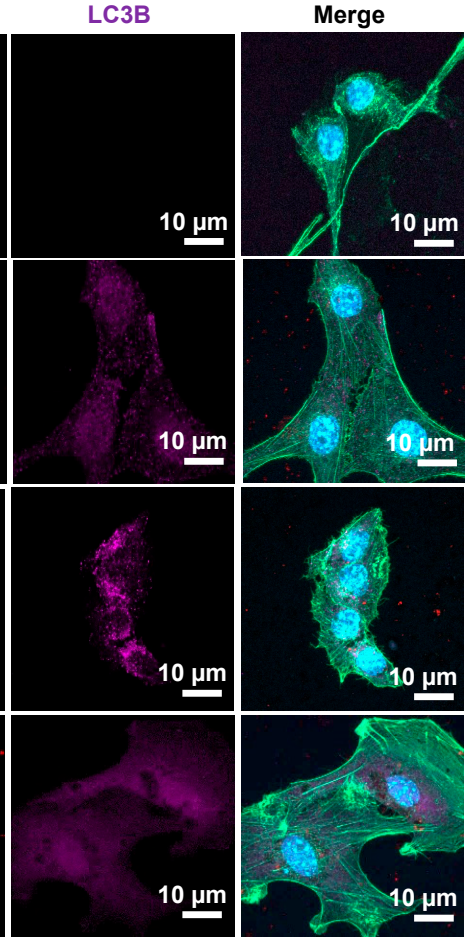

(b)

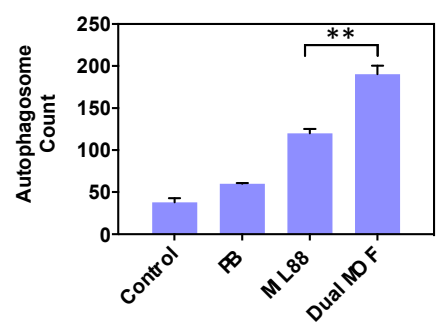

(c)

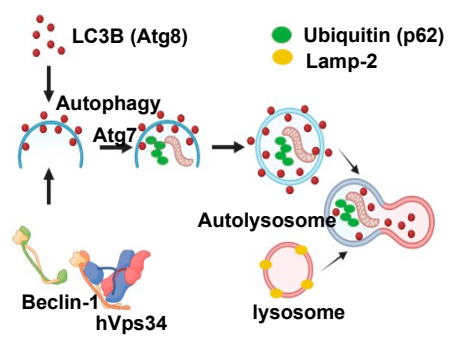

Figure 4. Autophagy activation through LC3B protein expression. (a) Confocal fluorescence images of B16F10 cells incubated with PB, MIL88, and MIL88@PB (100 $\mu \mathrm{g} / \mathrm{mL})$ (blue, green, and red fluorescence represent nucleus, cytoskeleton, and NP staining with DAPI, F-actin, and QD, respectively; purple fluorescence represents LC3B expression, which shows the quantity of autophagosomes), the experiment was conducted three times on three independent 6-well plates. (b) Autophagosome quantification of PB, MIL88, and MIL88@PB by image J analysis software. (c) Schematic representation showing increased LC3B expression leads to increased autophagy expression. Quantitative significant statistical data were calculated via Student's $t$-test, ${ }^{* *} p<0.01$. 


\subsection{CQ Inhibition of LC3B Protein Expression}

Having demonstrated the LC3B protein expression in B16F10 cells, the co-delivery of autophagy inhibitor (CQ) in MOFs was also investigated. The experiment was performed with dual MOFs, CQ alone, and CQ-dual MOF groups. CLSM images in Figure 5a exhibited the strong fluorescence expression of LC3B (purple fluorescence) in MIL88 and Dual MOFs groups once the particles co-delivering CQ. Compared to particles' groups, the CQ along group revealed the slightly LC3B expression, which might be caused by the autophagy inhibition effect. After quantifying the results, the CQ-loaded dual MOF groups demonstrated the increased autophagosome numbers (Figure $5 b$ ). Based on these results, the amounts of autophagosomes were not only affected by the sustained ROS generation but also the inhibition of degradation of resulting autolysosomes. As the literature documented, the unprotonated CQ can be soluble and diffuse freely in cell membranes and organelles [41,42]. When protonated in an acid environment, such as the lysosomal compartment, CQ would be trapped since the protonated form is insoluble in a lipid membrane. Because of protonation and accumulation of CQ in the lysosomal compartment, it would deplete hydrogen ions and change the internal environment, leading to blocking the degradation substrates in lysosomes and stopping the metabolization. This would inhibit normal lysosomal functioning, which has been demonstrated to be the main reason for blocking the fusion of autophagosomes with lysosomes [41,42]. The acidity-tropic nature of CQ promotes its accumulation and trapping in cancer cells, further facilitating its pharmacological autophagy inhibition. Such blocking effects by CQ combined with MOF on catalytic ROS generation, controlling the degradation of damaged cellular organelles, which leads to the oxidative damage induced by nanocatalytic therapy, and a significant increase in autophagosomes.

(a)
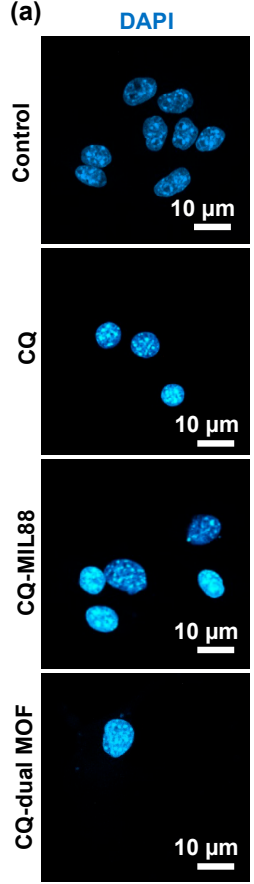

F-actin

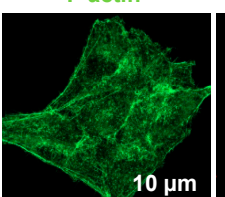

$10 \mu \mathrm{m}$
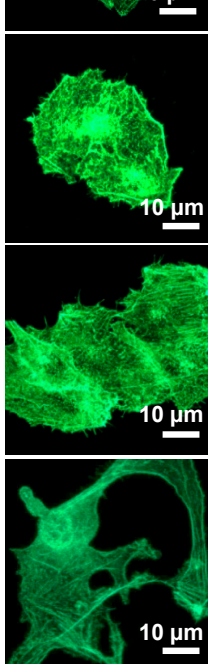

QD

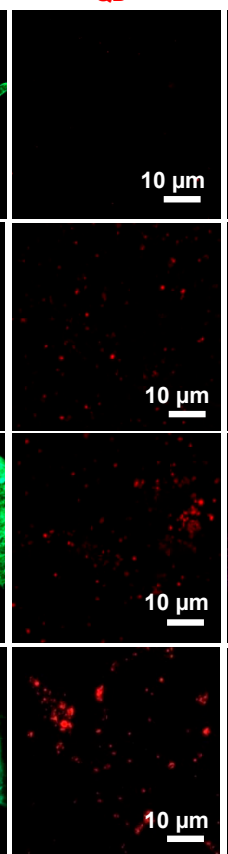

LC3B

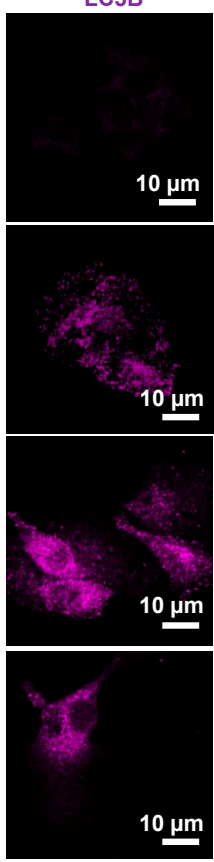

Merge

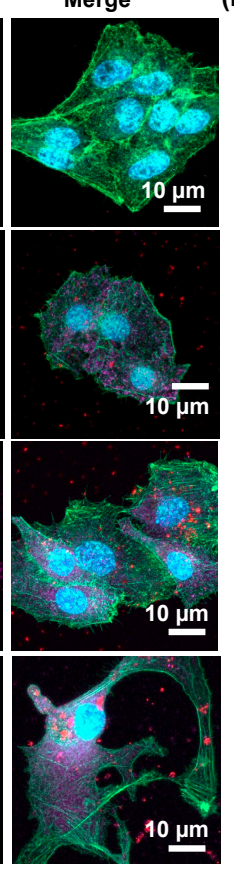

(b)

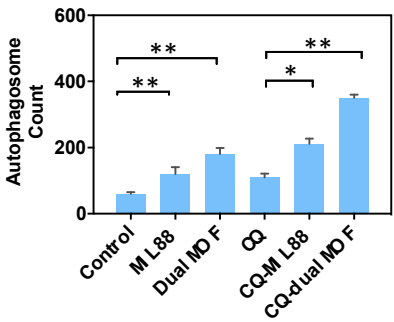

Figure 5. Autophagy regulation by CQ, CQ-MIL88, and CQ-dual MOF. (a) Confocal florescence images of B16F10 cells incubated with CQ, CQ-MIL88, and CQ-dual MOF $(100 \mu \mathrm{g} / \mathrm{mL})$. Purple florescence represents LC3B expression, which shows the quantity of autophagosomes. Blue, green, and red fluorescence represent nucleus, cytoskeleton, and NP staining with DAPI, F-actin, and QD, respectively. The experiment was conducted for three times on three independent 6-well plates. (b) The quantification of autophagosome of B16F10 cells incubated with CQ, CQ-MIL88, and CQdual MOF $(100 \mu \mathrm{g} / \mathrm{mL})$ by image J analysis software. Quantitative significant statistical data were calculated via Student's $t$-test, ${ }^{*} p<0.05,{ }^{* *} p<0.01$. 


\subsection{In Vivo Study of Mice Bearing Lung Metastasis Treated with Dual MOF}

The effects of particles on in vivo $\mathrm{T}$ cell recruitment in lung metastasis were investigated in mice bearing B16F10 lung metastases. For tracking purposes, PB, MIL88, and dual MOF were labeled in advance with QD. Figure 6a displayed the CLSM images of lung metastases after the tumor-bearing mice were treated with PB, MIL88, and dual MOF at $24 \mathrm{~h}$ post injection. Several results can be drawn by the results. First, three systems can accumulate in lung, which might be attributed by margination and EPR (enhanced permeation and retention) effects of particles [12]. Second, all groups exhibited a strong expression of $\mathrm{CD}^{+}$and $\mathrm{CD}^{+}$(the typical markers of the upregulation of the $\mathrm{T}$ cell surface and indicated immune activity) (Figure 6b). The accumulation of $\mathrm{T}$ cells can be understood by the ROS generation in the lungs, in which $\mathrm{Fe}^{2+}$ ions of MOF reacted with $\mathrm{H}_{2} \mathrm{O}_{2}$ in tumor environment and inactive the organelles and proteins for the aberrant accumulation. Further activation of autophagy increases the antigens that could load into MHC class I and II to induce direct cytotoxic reaction and produce immunoprotective properties in the tumor. Figure $6 c$ represented the enlarged images of CLSM exhibited CD4 ${ }^{+}$and CD $8{ }^{+}$expression in lung metastasis tumor, indicating the good distribution of $\mathrm{CD}^{+}$expressed cells.
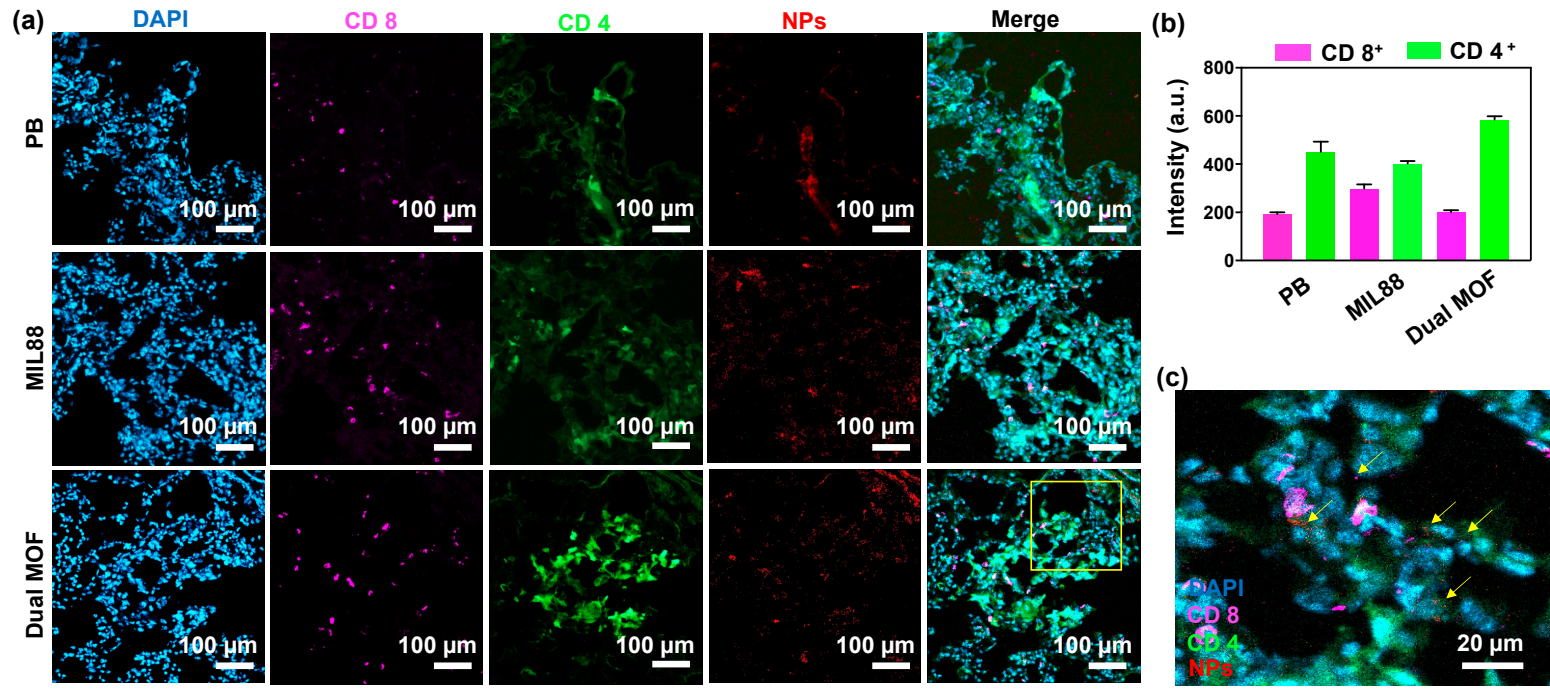

Figure 6. In vivo study of mice bearing B16F10 lung metastases treated with PB, MIL88, and dual MOF. (a) CLSM images of lung expressing $\mathrm{CD}^{+}$and $\mathrm{CD}^{+}$after treated with PB, MIL88, and dual MOF. Purple and green florescence represents $C D 4^{+}$and $C D 8^{+}$expressed cells. (b) Quantification of CD8 and CD4 expression by image J software. (c) The enlarged CLSM image of lung treated by dual MOF.

CQ-loaded MIL88 and dual MOF were injected intravenously to lung metastasisbearing mice to estimate the eliciting of T cells. As shown in Figure 7a, CLSM images of lung metastases-bearing mice treated with CQ-MIL88 and CQ-dual MOF at $24 \mathrm{~h}$ post injection exhibited many strong $\mathrm{CD}^{+}$and $\mathrm{CD}^{+}$expressed cells. The significant improvement of T cells could be understood by the combination effects of CQ and Fenton reactions. As previous described, CQ trapped in lysosomal compartment would deplete hydrogen ions and change the internal environment. It blocked the degradation substrates in lysosomes and stopped the metabolization, inhibiting the self-protection of autophagosomes. Therefore, it caused cell death and released tumor-associated antigens to elicit $\mathrm{T}$ cells to tumors. With the recruiting of T cell, the metastatic suppression effects of CQ-MIL88 and CQ-dual MOF were investigated by injecting $100 \mu \mathrm{L}$ of particles intravenously to lung metastasis-bearing mice at 7 days after tumor implantation. Subsequently, the tumor foci number was calculated after 14 days. The B16F10 metastasis is a type of aggressive tumors which prefers to colonize the distinct organs via circulation. The images in Figure $7 \mathrm{~b}$ revealed the macroscopic appearance of lungs treated by CQ-MIL88 and CQ-dual MOF. 
Compared to control group, the numbers of tumor nodules were decreased. After calculation, there were $\sim 440$ tumor foci in the control group, but fewer than 10 tumor foci were observed after CQ-MIL88 and CQ-dual MOF, indicating the preliminary suppression of the tumor. Flow cytometry also displayed the relative population of $\mathrm{T}$ cells after various treatments (Figure 7c). Compared to the PB group, the CQ-dual MOF possessing the effects on programmed ROS generation and autophagy inhibition displayed a three-fold greater of CD8+ expression. Such effective T cell eliciting also reflected to tumor inhibition in Figure $7 \mathrm{~b}$. The gating strategy of T cells in flow cytometry was given in Figure S3. In the literature, CQ effectively blocked autophagy at the lysosomal degradation step in mouse breast cancer cell lines, and targeting autophagy-inhibited melanoma tumor growth by inducing a massive infiltration of immune cells, including NK cells and CD8+ into B16-F10 tumor cells $[43,44]$. Compared to their results, our systems integrated to dual MOF and dysfunctional autophagy could elicit higher numbers of $\mathrm{T}$ lymphocytes at the metastasis.

(a)

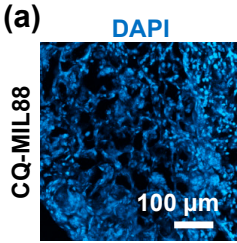

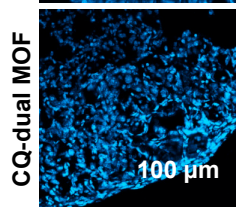

CD 8
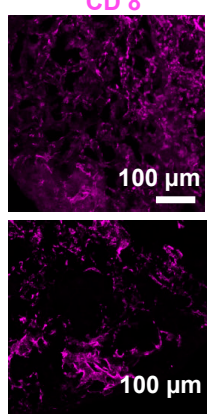
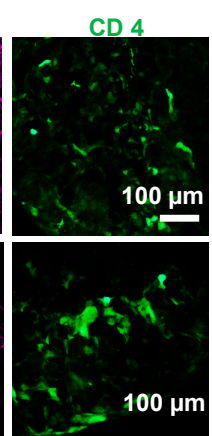
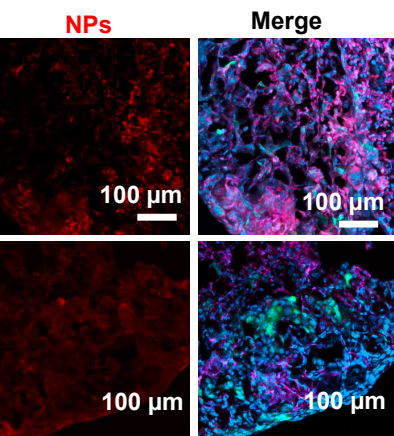

(b)
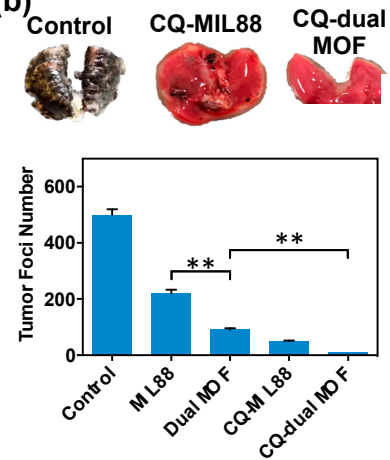

(c)

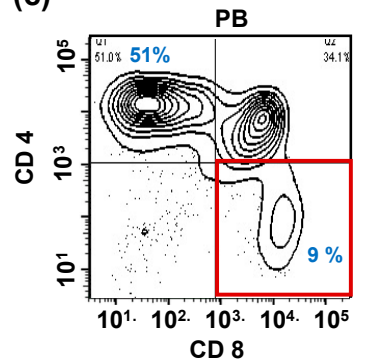

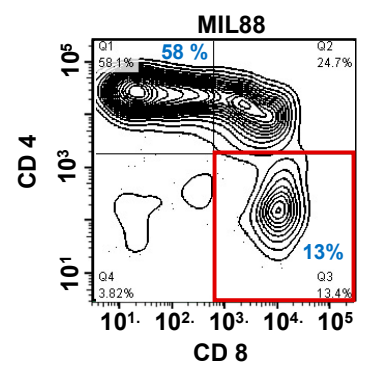

Dual MOF

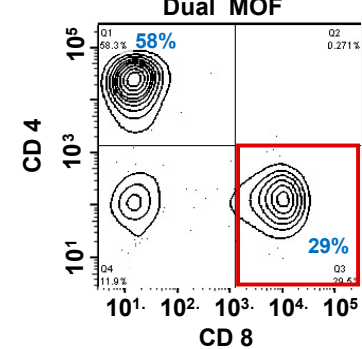

CQ-dual MOF

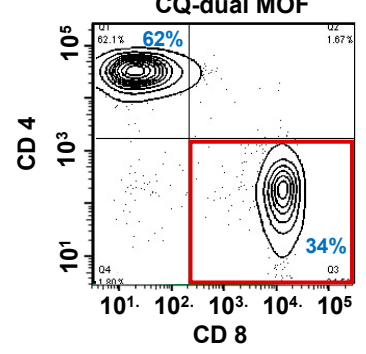

Figure 7. In vivo study of mice bearing B16F10 lung metastases treated with CQ-MIL88 and CQdual MOF. (a) CLSM images of lung metastases treated by CQ-MIL88 and CQ-dual MOF. (b) Images of dissected lung metastases treated by PBS (control), CQ-MIL88, and CQ-dual MOF. (c) Patterns of flow cytometry showing the $\mathrm{CD} 4^{+}$and $\mathrm{CD}^{+}$expression of $\mathrm{T}$ cells in lungs after various treatments. Quantitative significant statistical data were calculated via Student's $t$-test, ${ }^{* *} p<0.01$.

To understand the toxicity in vivo, both liver and kidney functions, including alanine aminotransferase (ALT), alkaline phosphatase (ALP), blood urea nitrogen (BUN), and serum creatinine (CRE), were evaluated $48 \mathrm{~h}$ post treatment. In brief, $100 \mu \mathrm{L}$ of solution containing with $0.5 \mathrm{wt} \%$ MIL88 or dual MOF was injected into 6- to 8-week-old female C57BL/ 6 mice intravenously. Then, $48 \mathrm{~h}$ post treatment, an analysis of blood biochemistry (ALT, ALP, BUN, and CRE) was performed by $20 \mu \mathrm{L}$ of whole blood withdrawn via submandibular through AmiShield (ProtectLife International Biomedical Inc., Taoyuan, Taiwan). Compared to the control group, only slight influence in liver and kidney functions was detected after treating MIL88 and dual MOF (Figure S4). On the other hand, despite the materials exhibiting potential in immune therapy, the limitations for translation into clinic need to be further overcome in the future. First, controlled drug release might be affected by tumor heterogeneity, including blood flow, $\mathrm{pH}$ variation, and oxygenation, leading to the decrease of responses and insufficient drug release. Second, the accumulation of 
materials in the tumor might also be limited because of the recognition of immune system and clearance of the reticuloendothelial or mononuclear phagocyte system. To translate the system to industrial application, the challenges in biological problems, scale-up of manufacturing, biosafety, regulations, and cost utility must be addressed.

\section{Conclusions}

A core-shell metal-organic framework nanocube composed of a Prussian blue core and $\mathrm{Fe}^{2+}$-containing metal-organic framework shell was developed to program reactive oxygen species and transported Chloroquine at a lung metastasis. The internalization-mediated cancer cell uptake exhibited the strong colocalization of nanocubes to cancer cells in vitro and in vivo. By co-delivering Chloroquine, the inhibition of autophagy through lysosomal deacidification was observed by MOF nanocubes, facilitating the block of the self-defense mechanism. At the tumor site, the core-shell nanocube with effective catalytic performance and dysfunctional autophagy elicited the $~ 3$-fold infiltration of T lymphocytes. The synergy of $\mathrm{T}$ cell recruitment and ROS generation transported by dual MOF in the metastatic tumors inhibit the tumor foci in lung. Such cube-shaped nanocatalytics may provide a new avenue for lung disease therapy, potentially leading to the effective clinical immune therapy.

Supplementary Materials: The following supporting information can be downloaded at: https: / / www.mdpi.com/article/10.3390/pharmaceutics14030527/s1, Figure S1. Colloidal stability of PB, MIL88 and dual MOF in DMEM + 10\% FBS over 24 h; Figure S2. CQ release patterns of PB, MIL88 and dual MOF; Figure S3. The gating strategy of T cells in flow cytometry; Figure S4. Liver function (ALT and ALP) and kidney function (BUN and CRE) at $48 \mathrm{~h}$ postinjection of PBS, MIL88 and dual $\operatorname{MOF}(n=5)$.

Author Contributions: Conceptualization, methodology, software, validation, B.N.Y., P.-H.C., T.M., T.M.H.H. and W.-H.C.; Formal analysis, investigation, B.N.Y., P.-H.C., T.M., T.M.H.H., W.-H.C. and S.-H.H.; resources, W.-H.C. and S.-H.H.; writing-original draft preparation, B.N.Y. and S.-H.H.; writing-review and editing, B.N.Y., W.-H.C. and S.-H.H. All authors have read and agreed to the published version of the manuscript.

Funding: This work was financially supported by the Ministry of Science and Technology of the Republic of China, Taiwan under contracts MOST 110-2636-E-007-001 and MOST 109-2636-E-007-014 and by National Tsing Hua University (110Q2514E1 and 110Q2535E1) in Taiwan. This work was also supported by a grant from the National Health Research Institutes (NHRI-EX111-11111EI).

Institutional Review Board Statement: The animal study protocol was approved by Institutional Animal Care and Use Committee (IACUC), National Tsing Hua University, Hsinchu, Taiwan (IACUC protocol and approval number is 10704).

Informed Consent Statement: Not applicable.

Data Availability Statement: Data are available upon reasonable request. All data relevant to the study are included in the article. The full data set is held by the corresponding author, please email with any requests for extra data.

Conflicts of Interest: The authors declare no conflict of interest, financial or otherwise.

\section{References}

1. Hynes, W.F.; Pepona, M.; Robertson, C.; Alvarado, J.; Dubbin, K.; Triplett, M.; Adorno, J.J.; Randles, A.; Moya, M.L. Examining metastatic behavior within 3D bioprinted vasculature for the validation of a 3D computational flow model. Sci. Adv. 2020, 6, eabb3308. [CrossRef] [PubMed]

2. Quiroz-Reyes, A.G.; Islas, J.F.; Delgado-Gonzalez, P.; Franco-Villarreal, H.; Garza-Treviño, E.N. Therapeutic Approaches for Metastases from Colorectal Cancer and Pancreatic Ductal Carcinoma. Pharmaceutics 2021, 13, 103. [CrossRef] [PubMed]

3. Ibaraki, H.; Kanazawa, T.; Owada, M.; Iwaya, K.; Takashima, Y.; Seta, Y. Anti-Metastatic Effects on Melanoma via Intravenous Administration of Anti-NF-kB siRNA Complexed with Functional Peptide-Modified Nano-Micelles. Pharmaceutics 2020, 12, 64. [CrossRef] [PubMed]

4. Bergers, G.; Fendt, S.M. The metabolism of cancer cells during metastasis. Nat. Rev. Cancer 2021, 21, 162. [CrossRef]

5. Ganesh, K.; Massagué, J. Targeting metastatic cancer. Nat. Med. 2021, 27, 34. [CrossRef] 
6. Joseph, R.; Soundararajan, R.; Vasaikar, S.; Yang, F.; Allton, K.L.; Tian, L.; den Hollander, P.; Isgandarova, S.; Haemmerle, M.; Mino, B.; et al. CD8 ${ }^{+}$T cells inhibit metastasis and CXCL4 regulates its function. Br. J. Cancer. 2021, 125, 176. [CrossRef]

7. Lôbo, G.C.N.B.; Paiva, K.L.R.; Silva, A.L.G.; Simões, M.M.; Radicchi, M.A.; Báo, S.N. Nanocarriers Used in Drug Delivery to Enhance Immune System in Cancer Therapy. Pharmaceutics 2021, 13, 1167. [CrossRef]

8. Huis in 't Veld, R.V.; da Silva, C.G.; Jager, M.J.; Cruz, L.J.; Ossendorp, F. Combining Photodynamic Therapy with Immunostimulatory Nanoparticles Elicits Effective Anti-Tumor Immune Responses in Preclinical Murine Models. Pharmaceutics 2021, 13, 1470. [CrossRef]

9. Blanco, E.; Shen, H.; Ferrari, M. Principles of nanoparticle design for overcoming biological barriers to drug delivery. Nat. Biotechnol. 2015, 33, 941. [CrossRef]

10. Zhang, Y.X.; Zhao, Y.Y.; Shen, J.; Sun, X.; Liu, Y.; Liu, H.; Wang, Y.; Wang, J. Nanoenabled modulation of acidic tumor microenvironment reverses anergy of infiltrating T cells and potentiates anti-PD-1 therapy. Nano Lett. 2019, 19, 2774. [CrossRef]

11. Chiang, M.R.; Su, Y.L.; Chang, C.Y.; Chang, C.W.; Hu, S.H. Lung metastasis-targeted donut-shaped nanostructures shuttled by the margination effect for the PolyDox generation-mediated penetrative delivery into deep tumors. Mater. Horiz. $2020,7,1051$. [CrossRef]

12. Shen, W.T.; Hsu, R.S.; Fang, J.H.; Hu, P.F.; Chiang, C.S.; Hu, S.H. Marginative delivery-mediated extracellular leakiness and T cell infiltration in lung metastasis by a biomimetic nanoraspberry. Nano Lett. 2021, 21, 1375. [CrossRef] [PubMed]

13. Wieczorek, M.; Abualrous, E.T.; Sticht, J.; Álvaro-Benito, M.; Stolzenberg, S.; Noé, F.; Freund, C. Major histocompatibility complex (MHC) class I and MHC class II proteins: Conformational plasticity in antigen presentation. Front. Immunol. $2017,8,292$. [CrossRef] [PubMed]

14. Ostroumov, D.; Fekete-Drimusz, N.; Saborowski, M.; Kühnel, F.; Woller, N. CD4 and CD8 T lymphocyte interplay in controlling tumor growth. Cell Mol. Life Sci. 2018, 75, 689. [CrossRef] [PubMed]

15. Cairns, R.A.; Harris, I.S.; Mak, T.W. Regulation of cancer cell metabolism. Nat. Rev. Cancer. 2011, 11, 85. [CrossRef] [PubMed]

16. Chung, K.-S.; Yoo, C.-B.; Lee, J.-H.; Lee, H.-H.; Park, S.-E.; Han, H.-S.; Lee, S.-Y.; Kwon, B.-M.; Choi, J.-H.; Lee, K.-T. Regulation of ROS-Dependent JNK Pathway by 2'-Hydroxycinnamaldehyde Inducing Apoptosis in Human Promyelocytic HL-60 Leukemia Cells. Pharmaceutics 2021, 13, 1794. [CrossRef]

17. Tao, W.; He, Z. ROS-responsive drug delivery systems for biomedical applications. Asian J. Pharm. Sci. 2018, 13, 101. [CrossRef] [PubMed]

18. Yang, B.; Chen, Y.; Shi, J. Nanocatalytic medicine. Adv. Mater. 2019, 31, e1901778. [CrossRef]

19. Nirosha Yalamandala, B.; Shen, W.T.; Min, S.H.; Chiang, W.H.; Chang, S.J.; Hu, S.H. Advances in functional metal-organic frameworks based on-demand drug delivery systems for tumor therapeutics. Adv. NanoBiomed. Res. 2021, 1, 2100014. [CrossRef]

20. Yang, B.; Chen, Y.; Shi, J. Reactive oxygen species (ROS)-based nanomedicine. Chem. Rev. 2019, 119, 4881. [CrossRef]

21. White, E. Deconvoluting the context-dependent role for autophagy in cancer. Nat. Rev. Cancer 2012, 12, 401. [CrossRef] [PubMed]

22. Rivas-García, L.; Quiles, J.L.; Varela-López, A.; Giampieri, F.; Battino, M.; Bettmer, J.; Montes-Bayón, M.; Llopis, J.; SánchezGonzález, C. Ultra-Small Iron Nanoparticles Target Mitochondria Inducing Autophagy, Acting on Mitochondrial DNA and Reducing Respiration. Pharmaceutics 2021, 13, 90. [CrossRef] [PubMed]

23. Sumkhemthong, S.; Prompetchara, E.; Chanvorachote, P.; Chaotham, C. Cisplatin-induced hydroxyl radicals mediate pro-survival autophagy in human lung cancer H460 cells. Biol. Res. 2021, 54, 22. [CrossRef] [PubMed]

24. Yang, Z.; Klionsky, D.J. An overview of the molecular mechanism of autophagy. Curr. Top. Microbiol. Immunol. $2009,335,1$.

25. Li, X.; He, S.; Ma, B. Autophagy and autophagy-related proteins in cancer. Mol. Cancer 2020, 19, 12. [CrossRef]

26. Sheng, S.; Liu, F.; Lin, L.; Yan, N.; Wang, Y.; Xu, C.; Tian, H.; Chen, X. Nanozyme-mediated cascade reaction based on metal-organic framework for synergetic chemo-photodynamic tumor therapy. J. Control. Release 2020, 328, 631. [CrossRef]

27. Hu, P.; Wu, T.; Fan, W.; Chen, L.; Liu, Y.; Ni, D.; Bu, W.; Shi, J. Near infrared-assisted Fenton reaction for tumor-specific and mitochondrial DNA-targeted photochemotherapy. Biomaterials 2017, 141, 86. [CrossRef]

28. Wang, T.; Zhang, H.; Liu, H.; Yuan, Q.; Ren, F.; Han, Y.; Sun, Q.; Li, Z.; Gao, M. Boosting $\mathrm{H}_{2} \mathrm{O}_{2}$-guided chemodynamic therapy of cancer by enhancing reaction kinetics through versatile biomimetic fenton nanocatalysts and the second near-infrared light irradiation. Adv. Funct. Mater. 2020, 30, 1906128. [CrossRef]

29. Lin, X.; Liu, S.; Zhang, X.; Zhu, R.; Chen, S.; Chen, X.; Song, J.; Yang, H. An ultrasound activated vesicle of janus Au-MnO nanoparticles for promoted tumor penetration and sono-chemodynamic therapy of orthotopic liver cancer. Angew. Chem. Int. Ed. 2020, 59, 1682. [CrossRef]

30. Warhurst, D.; Hockley, D. Mode of Action of Chloroquine on Plasmodium berghei and P. cynomolgi. Nature 1967, $214,935$. [CrossRef]

31. Wu, T.T.; Li, W.M.; Yao, Y.M. Interactions between autophagy and inhibitory cytokines. Int. J. Biol. Sci. 2016, 12, 884. [CrossRef] [PubMed]

32. Germic, N.; Frangez, Z.; Yousefi, S.; Simon, H.U. Regulation of the innate immune system by autophagy: Monocytes, macrophages, dendritic cells and antigen presentation. Cell Death Differ. 2019, 26, 715. [CrossRef] [PubMed]

33. Ge, Y.; Huang, M.; Yao, Y.M. Autophagy and proinflammatory cytokines: Interactions and clinical implications. Cytokine Growth Factor Rev. 2018, 43, 38. [CrossRef] [PubMed] 
34. Ligeon, L.A.; Pena-Francesch, M.; Vanoaica, L.D.; Núñez, N.G.; Talwar, D.; Dick, T.P.; Münz, C. Oxidation inhibits autophagy protein deconjugation from phagosomes to sustain MHC class II restricted antigen presentation. Nat. Commun. 2021, 12, 1508. [CrossRef] [PubMed]

35. Hu, M.; Furukawa, S.; Ohtani, R.; Sukegawa, H.; Nemoto, Y.; Reboul, J.; Kitagawa, S.; Yamauchi, Y. Synthesis of Prussian blue nanoparticles with a hollow interior by controlled chemical etching. Angew. Chem. 2012, 51, 984. [CrossRef]

36. Guo, M.; Li, H. The Hydrolyzed Mil-88B(Fe) With improved surface area for high-capacity lithium ion battery. Front. Energy Res. 2021, 9, 781008. [CrossRef]

37. Liu, X.; Wu, F.; Tian, Y.; Wu, M.; Zhou, Q.; Jiang, S.; Niu, Z. Size dependent cellular uptake of rod-like bionanoparticles with different aspect ratios. Sci. Rep. 2016, 6, 24567. [CrossRef]

38. Foroozandeh, P.; Aziz, A.A. Insight into cellular uptake and intracellular trafficking of nanoparticles. Nanoscale Res. Lett. 2018, 13, 339. [CrossRef]

39. Breus, V.V.; Pietuch, A.; Tarantola, M.; Basché, T.; Janshoff, A. The effect of surface charge on nonspecific uptake and cytotoxicity of. CdSe/ZnS core/shell quantum dots. J. Nanotechnol. 2015, 6, 281. [CrossRef]

40. Gao, W.; Ding, W.X.; Stolz, D.B.; Yin, X.M. Induction of macroautophagy by exogenously introduced calcium. Autophagy 2008, 4, 754. [CrossRef]

41. Yang, B.; Ding, L.; Yao, H.; Chen, Y.; Shi, J. A Metal-Organic Framework (MOF) Fenton Nanoagent-Enabled Nanocatalytic Cancer Therapy in Synergy with Autophagy Inhibition. Adv. Mater. 2020, 32, 1907152. [CrossRef] [PubMed]

42. Mauthe, M.; Orhon, I.; Rocchi, C.; Zhou, X.; Luhr, M.; Hijlkema, K.J.; Coppes, R.P.; Engedal, N.; Mari, M.; Reggiori, F. Chloroquine inhibits autophagic flux by decreasing autophagosome-lysosome fusion. Autophagy 2018, 14, 1435. [CrossRef] [PubMed]

43. Maycotte, P.; Aryal, S.; Cummings, C.T.; Thorburn, J.; Morgan, M.J.; Thorburn, A. Chloroquine sensitizes breast cancer cells to chemotherapy independent of autophagy. Autophagy 2012, 8, 200. [CrossRef] [PubMed]

44. Noman, M.Z.; Parpal, S.; Moer, K.V.; Xiao, M.; Yu, Y.; Vinlund, J.; Milito, A.D.; Hasmin, M.; Andersson, M.; Amaravadi, R.K.; et al. Inhibition of Vps34 reprograms cold into hot inflamed tumors and improves anti-PD-1/PD-L1 immunothearpy. Sci. Adv. 2020, 6, 18. [CrossRef] [PubMed] 